\title{
Respiratory High-Dependency Care Units in Italy
}

Patients with chronic respiratory failure may require intensive care unit (ICU) admission to overcome severe episodes of acute-on-chronic respiratory failure with ventilatory assistance. ${ }^{1}$ However, ICUs are expensive resources. $^{2}$ A high proportion of patients with acute-onchronic respiratory failure in the ICU do not require invasive ventilation and may be treated with noninvasive ventilation (NIV), ${ }^{3}$ or need prolonged stay due to difficult or prolonged weaning. ${ }^{4}$ Furthermore, new technologies and improved care have increased the number of survivors of catastrophic illness in the ICU, and such patients often require prolonged weaning. ${ }^{5}$

NIV is currently a first-line intervention for patients with severe acute-on-chronic respiratory failure ${ }^{3,6}$ as well as to facilitate weaning and extubation. ${ }^{7,8}$ Respiratory highdependence care units (RHDCUs) are expected to relieve bed shortages in the ICU, to provide a high level of nursing assistance, to manage patients with acute-on-chronic respiratory failure who need NIV, to provide a multidisciplinary rehabilitative approach, and to serve as bridge to home-care programs or long-term care facilities. ${ }^{9-11}$

See the Original Study on Page 1100

In this issue of Respiratory Care, Scala and colleagues report an Italian national survey performed in 2007 that analyzed the temporal trends in the number, structures, staff, procedures, diagnosis, and outcomes of RHDCU in Italy, ${ }^{12}$ and compare their findings to the previous Italian national RHDCU survey in 1997. ${ }^{13}$ The RHDCUs were classified according to a European Respiratory Society task force report that defined 3 different levels of care: respiratory intensive care unit, respiratory intermediate care unit, and respiratory monitoring units. ${ }^{11}$ The 2007 survey ${ }^{12}$ found an increase in the total number of RHDCUs, that the patients in the RHDCUs were more complex than in 1997, and that there has been a reduction in the RHDCUs' medical and nursing staff resources.

The overall staff reduction was due in part to the fact that the increase in the number of RHDCUs was mainly an increase in the number of respiratory monitoring units, which by definition have fewer staff and less equipment than the intermediate and intensive types of units. However, there was a trend of reduction in staff resources in the period 1997 to 2007 for all 3 RHDCU levels. A similar trend of an increase in the complexity of patients and decrease in staff resources between 1991 and 2005 was recently reported by 5 Italian respiratory ICUs in Northern Italy,${ }^{14}$ which were among the RHDCUs described by Scala and colleagues. ${ }^{12} \mathrm{~A}$ worsening in the main clinical outcomes of patients admitted to these units was associated with the reduced numbers of doctors, and drew attention to the potential further negative influence of reduced staffing on the rates of weaning success and home discharge, and stay. ${ }^{14}$

Contrary to what might be expected, the association of more active interventions (including NIV and invasive ventilation, weaning from invasive ventilation, and tracheal decannulation), as opposed to monitoring only, increased the complexity of the care of the patients admitted, but the staffing reduction described by Scala and colleagues ${ }^{12}$ did not result in worse clinical outcomes, compared to the previous survey. This may reflect an increase in Italian RHDCUs' expertise in dealing with critically ill patients, despite the finding that the most prevalent growth was in the lower-level (ie, respiratory monitoring) units, as Scala et al point out.

In line with these observations, a recent survey on the perceptions and practices of Italian pulmonologists, intensivists, and emergency department physicians regarding $\mathrm{NIV}^{15}$ found similarities with the survey by Scala and colleagues. ${ }^{12}$ First, the most frequent type of patients admitted to the RHDCUs were those with acute-on-chronic respiratory failure, including patients with COPD, obesityhypoventilation, and chest-wall disease, ${ }^{12}$ similar to the fact that patients with acute-on-chronic respiratory failure were preferentially managed by pulmonologists instead of intensivists or emergency physicians in Italy. ${ }^{15}$ Second, the majority of RHDCUs identified in the 2007 survey belonged to non-university hospitals. ${ }^{12}$ Similarly, despite the fact that the large majority of randomized controlled trials on NIV use have been done in teaching hospitals, the pattern of NIV use was quite similar between the physicians working in university hospitals versus community hospitals in the various scenarios in the recent survey. ${ }^{15}$ This probably reflects Italian physicians' awareness of the current literature on NIV and its efficacy in clinical settings, which explains the widespread use of NIV in nonuniversity hospitals.

The study by Scala et al has the usual limitations of surveys, including that the information collected from the 


\section{Respiratory High-Dependency Care Units in Italy}

respondents cannot be contrasted. ${ }^{12}$ As Scala et al state, changes in clinical practice between 1997 and 2007 may limit the comparability of the 2 surveys and may have favored the current survey. Moreover, they collected no data on the financial impact of RHDCUs on ICU and overall hospital resources, which prevents drawing direct economic conclusions from the survey. However, the findings of this ${ }^{12}$ and the previous survey ${ }^{15}$ reflect the high level of expertise and skills of physicians in Italian RHDCUs in managing patients who need NIV.

\section{Miquel Ferrer MD}

Unitat de Vigilància Intensiva Respiratoria

Servei de Pneumología

Institut del Tórax

Hospital Clínic IDIBAPS

Universitat de Barcelona

Barcelona, Spain

\section{REFERENCES}

1. Esteban A, Anzueto A, Alía I, Gordo F, Apezteguía C, Palízas F et al. How is mechanical ventilation employed in the intensive care unit? An international utilization review. Am J Respir Crit Care Med 2000;161(5):1450-1458.

2. Wagner DP. Economics of prolonged mechanical ventilation. Am Rev Respir Dis 1989;140(2 Pt 2):S14-S18.

Dr Ferrer's research was partly supported by Centro de Investigación en Red de Enfermedades Respiratorias grant CB06/06/0028)-ISCiii, 2009 SGR 911. He has reported no other conflicts of interest.

Correspondence: Miquel Ferrer MD, Unitat de Vigilància Intensiva Respiratoria, Servei de Pneumología, Institut del Tórax, Hospital Clínic IDIBAPS, Universitat de Barcelona, Villarroel 170, 08036 Barcelona, Spain. E-mail: miferrer@clinic.ub.es.

DOI: $10.4187 /$ respcare. 01455
3. Lightowler JV, Wedzicha JA, Elliott MW, Ram FS. Non-invasive positive pressure ventilation to treat respiratory failure resulting from exacerbations of chronic obstructive pulmonary disease: Cochrane systematic review and meta-analysis. BMJ 2003;326(7382):185-189.

4. Boles JM, Bion J, Connors A, Herridge M, Marsh B, Melot C, et al. Weaning from mechanical ventilation. Eur Respir J 2007;29(5): 1033 1056.

5. Esteban A, Alía I, Ibañez J, Benito S, Tobin MJ; Spanish Lung Failure Collaborative Group. Modes of mechanical ventilation and weaning. A national survey of Spanish hospitals. Chest 1994;106(4): 1188-1193.

6. Nava S, Hill N. Non-invasive ventilation in acute respiratory failure. Lancet 2009;374(9685):250-259.

7. Burns KE, Adhikari NK, Keenan SP, Meade M. Use of non-invasive ventilation to wean critically ill adults off invasive ventilation: metaanalysis and systematic review. BMJ 2009;338:b1574. doi: 10.1136/ bmj.b1574.

8. Ferrer M, Sellarés J, Valencia M, Carrillo A, Gonzalez G, Badia JR, et al. Non-invasive ventilation after extubation in hypercapnic patients with chronic respiratory disorders: randomised controlled trial. Lancet 2009;374(9695):1082-1088.

9. Nava S, Vitacca M. Chronic ventilatory facilities. In: Tobin MJ, editor. Principles and practice of mechanical ventilation, 2nd edition. New York: McGraw-Hill; 2006:691-704.

10. Rossi A, Ambrosino N. The need for an intermediate cardiorespiratory unit. Monaldi Arch Chest Dis 1994;49(6):463-465.

11. Corrado A, Roussos C, Ambrosino N, Confalonieri M, Cuvelier A, Elliott M, et al. Respiratory intermediate care units: a European survey. Eur Respir J 2002;20(5):1343-1350.

12. Scala R, Corrado A, Confalonieri M, Marchese S, Ambrosino N. Increased number and expertise of Italian respiratory high-dependency care units: the second national survey. Respir Care 2011; 56(8):1100-1107.

13. Confalonieri M, Gorini M, Ambrosino N, Mollica C, Corrado A; Scientific Group on Respiratory Intensive Care of the Italian Association of Hospital Pneumonologists. Respiratory intensive care units in Italy: a national census and prospective cohort study. Thorax 2001;56(5):373-378

14. Polverino E, Nava S, Ferrer M, Ceriana P, Clini E, Spada E, et al. Patients' characterization, hospital course and clinical outcomes in five Italian respiratory intensive care units. Intensive Care Med 2010; 36(1):137-142.

15. Crimi C, Noto A, Princi P, Nava S. Survey of non-invasive ventilation practices: a snapshot of Italian practice. Minerva Anestesiol. 2011 May 20. [Epub ahead of print] 